\title{
Type 2 diabetes mellitus risk assessment among doctors in Ondo state
}

\section{Adenike Christianah Enikuomehin ${ }^{1}$, Oluseyi Ademola Adejumo${ }^{1}$, Ayodeji Akinwumi Akinbodewa ${ }^{1}$, Fakhraddeen Yahya Muhammad ${ }^{2}$, Olutoyin Morenike Lawal ${ }^{2}$, Oladimeji Adedeji Junaid ${ }^{1}$}

1. Department of Internal Medicine, University of Medical Sciences, Ondo State

2. Department of Internal Medicine, Muhammad Abdullahi Wase Specialist Hospital, Kano State

Corresponding author; Dr O. A Adejumo; (ceeward2010@yahoo.com)

\begin{abstract}
Introduction

Diabetes Mellitus (DM) has become a disease of public health importance in Nigeria. Early identification of DM risk is important in the reduction of this disease burden. This study assessed ten-year risk of developing type 2 DM among some medical doctors in Ondo State.

Methods

This was a cross-sectional study that assessed ten-year risk of developing type 2 DM among some doctors using the Finland Diabetic Risk Score form. Known diabetics were excluded from the study. Body mass index (BMI), waist circumference (WC), blood pressure and total DM risk score were determined for each participant.

Results

One hundred and ninety-two doctors participated in the study with a male: female ratio of 1.3:1. Majority (92.2\%) were below 55 years, $22(11.5 \%)$ were obese, 32(16.7\%) had central obesity, 46(24\%) reported physical inactivity, 49(25.5\%) had family history of DM, $141(73.4 \%)$ do not take fruits and vegetables regularly. Forty-three $(22.4 \%)$ were found to have elevated blood pressure while $6(3.1 \%)$ had elevated blood glucose. Fifty-seven $(29.7 \%)$ of the participants had increased ten-year DM risk. Significant predictors of increase DM risk were age $\geq 45$ years (AOR:9.08; CI 3.13-26.33; $\mathrm{p}=<0.001$ ) ; BMI $\geq 25 \mathrm{~kg} / \mathrm{m}^{2}$ (AOR:11.41; CI:4.14-31.45; $\left.\mathrm{p}=<0.001\right) ;$ family history of DM (AOR:9.93; CI:3.25-30.39; $\mathrm{p}=<0.001$ ) ; abdominal obesity (AOR:6.66; CI:2.08-21.29; $\mathrm{p}=<0.001$ ); and infrequent dietary intake of fruits and vegetable(AOR:3.11;CI:1.03:9.37: $\mathrm{p}=0.04)$

\section{Conclusion}

There was increased 10 -year DM risk in about 30\% of the participants. Lifestyle modification such as physical activity and regular consumption of fruits and vegetables should be encouraged among doctors.
\end{abstract}

Keywords: type 2 diabetes mellitus, risk, doctor, nigeria

\section{Introduction}

Diabetes mellitus (DM) is a disease of public health importance worldwide. The prevalence has continued to increase in developing countries including Nigeria ${ }^{1}$. Globally, 382 million people which constitute $8.3 \%$ of adult population had DM by the end of 2013 according to International Diabetes Federation (IDF) ${ }^{2}$. About $80 \%$ of this population lived in the low and middle income countries. It is also projected that this number will reach 592 million by year 2035 if preventive measures are not put in place $^{2}$.

About twenty million people in sub-Saharan Africa have diabetes and only one-third is diagnosed ${ }^{2}$. The IDF projected that DM may affect about 41.4 million people by $2035^{2}$. In Nigeria, there has been an increase in the prevalence of DM affecting of all geographical zones. In a systematic review and Met-analysis done by Uloko et $\mathrm{al}^{1}$ in 2017, the pooled prevalence of DM in Nigeria was found to be $5.77 \%$.

DM is associated with high morbidity, mortality and huge economic burden even in the developed countries. Chineye et $\mathrm{al}^{3}$ studied 531 diabetic patients in seven Nigerian tertiary hospitals and found high prevalence of different complications; peripheral neuropathy (59.2\%), retinopathy
$(35.5 \%)$, cataracts $(25.2 \%)$, cerebrovascular disease $(4.7 \%)$, diabetic foot ulcers (16.0\%), and nephropathy $(3.2 \%)$. Hyperglycemic emergencies which are amongst the common indications for DM related hospitalization is associated with high case fatality in Nigeria ${ }^{4,5}$. Approximately onehalf of patients with type 2 diabetes die prematurely of a cardiovascular cause while $10 \%$ die of renal failure ${ }^{6}$. There is projection that the absolute global economic burden of DM will increase from 1.3 trillion USD to about 2.1 trillion USD by $2030^{7}$. There is also reduction in overall quality of life of DM patients ${ }^{8,9}$. Prevention and early diagnosis of DM are important and effective strategies in reducing the global burden of the disease.

Medical doctors play key role in ensuring optimal health of the citizens of a nation which is important for economic growth. Despite their medical knowledge, medical doctors have a tendency to present late when they have any medical illness because majority of them have poor health seeking attitude $^{10}$. This study assessed medical doctors for type 2 diabetic risk during the continuing medical education (CME) program organized by the Nigerian Medical Association. Those with increased risk of diabetes mellitus 
were identified, offered health education and counseling on lifestyle modification aimed at reducing this risk.

\section{Materials and Methods \\ Study Design}

This was a cross-sectional study carried out during a continuing medical education program organized by Nigerian Medical Association in 2019. The study was conducted among medical doctors working in Ondo State, South-western Nigeria.

\section{Study Sample Size}

The minimum sample size for this study was calculated using the prevalence of DM among doctors from a previous study as $11.1 \%$, a value of $95 \%$ confidence level and an error margin of $5 \%{ }^{11}$. A minimum sample size of 152 was obtained, however 192 medical doctors participated in the study

\section{Study Participant}

Consenting medical doctors who attended the continuing medical education organized by the Nigerian Medical Association were consecutively recruited in the study. Those who were previously diagnosed diabetic were excluded. The study participants were assessed for 10 year risk of developing type $2 \mathrm{DM}$ using an interviewer administered Finland Diabetic Risk Score (FINDRISC score) form. This form has been recommended by the International Diabetes Federation as a cheap and valid screening tool for type 2DM in resource limited settings ${ }^{12}$. This diabetic risk assessment form has been previously validated among Africans; showing $77 \%$ sensitivity, $89 \%$ specificity and that the area under the ROC curve was $0.86^{13}$.

The questionnaire contained eight simple questions that assessed risk factors for T2DM. These risk factors were age (years), body mass index $\left(\mathrm{kg} / \mathrm{m}^{2}\right)$, waist circumference $(\mathrm{cm})$, daily consumption of fruits or vegetables, daily physical activity (having at least 30 minutes of physical activity during work or at leisure time), history of antihypertensive drug treatment, history of high blood glucose, and family history of diabetes mellitus in the first-degree or second-degree relatives. Each of these was assigned with weighted scores according to its associated risk, and the final scores range from 0 to 26 points. The total score was used to categorize the 10 year risk of each participant of developing DM as follows; $<7$ points as low risk, $7-11$ points as slightly elevated risk, $12-14$ points as moderate risk; $15-20$ points as high risk and $>20$ points as very high risk.

Blood pressure was measured on the right arm using the mercury sphygmomanometer (Accoson, Harlow, United Kingdom) with a standard cuff size and the participants in sitting position after about $5 \mathrm{~min}$ of rest. Elevated blood pressure was defined as blood pressure value of $\geq 140 / 90 \mathrm{mmHg}$ on measurement. Waist circumference (WC) was measured at a point midway between the lowest rib and the iliac crest. Abdominal obesity was defined as WC $>102 \mathrm{~cm}$ in males and $88 \mathrm{~cm}$ in females. The height and weight of participants were measured using a stadiometer (RGZ 160 Lincon Mark Medical, England). Body mass index (BMI) was calculated from the weight and height and expressed as $\mathrm{kg} / \mathrm{m}^{2}$. BMI of between $25-29.9 \mathrm{~kg} / \mathrm{m}^{2}$ was categorized as overweight and $\geq 30 \mathrm{~kg} / \mathrm{m}^{2}$ was categorized as obese. Determination of random blood glucose was done for each participant using ACC Check glucose meter. Elevated random blood glucose was defined as blood glucose greater than $200 \mathrm{mg} / \mathrm{dl}$.

Ethical approval was obtained from the Research and Ethical Committee of University of Medical Sciences, Ondo.withn a protocol number HREC/01/2019/VII/4616

\section{Data Analysis}

Data entry and analysis was done using IBM Statistical Package for Social Science version 21. Categorical variables were expressed as frequencies and proportions. Data were displayed in tables and charts. Univariate analysis was used to determine significant factors associated with increased type 2 DM risk. Binary logistic regression analysis was used to determine the significant predictors of increased type $2 \mathrm{DM}$ risk. Pearson's correlation analysis was used to determine association between random blood glucose, BMI, abdominal circumference, age and total diabetic risk score. P value of $\leq 0.05$ was considered significant.

\section{Results}

One hundred and ninety-two doctors participated in the study comprising of 110 males $(57.3 \%)$ and 82 females $(42.7 \%)$. One hundred and twenty-four $(64.6 \%)$ were below 45 years. (Table 1 )

\section{Table 1: Characteristics of Study Participants}

\begin{tabular}{|l|c|}
\hline Characteristics & $\mathrm{n}(\%)$ \\
\hline Age Group & $124(64.6 \%)$ \\
\hline$<45$ years & $53(27.6 \%)$ \\
\hline $45-64$ years & $15(7.8 \%)$ \\
\hline$>64$ years & \\
\hline Gender & $110(57.3 \%)$ \\
\hline Male & $82(42.7 \%)$ \\
\hline Female & $120(62.5 \%)$ \\
\hline Body Mass Index $\left(\mathrm{Kg} / \mathrm{m}^{2}\right)$ & $50(26.0 \%)$ \\
\hline$<25$ & $22(11.5 \%)$ \\
\hline $25-29.9$ & \\
\hline$\geq 30$ & $32(16.7 \%)$ \\
\hline AbdominalObesity & $160(83.3 \%)$ \\
\hline Yes & \\
\hline No & $146(76.0 \%)$ \\
\hline Physical Activity & $46(24.0 \%)$ \\
\hline Yes & \\
\hline No & \\
\hline Daily Consumption of & $184(96.9 \%)$ \\
\hline Vegetables/Fruits & $51(26.6 \%)$ \\
\hline Yes & $141(73.4)$ \\
\hline No & \\
\hline Family History of Diabetes & $49(25.5 \%)$ \\
\hline Mellitus & $143(74.5 \%)$ \\
\hline No & $43(22.4 \%)$ \\
\hline Elevated Blood Pressure & $149(77.6 \%)$ \\
\hline Yes & \\
\hline No & \\
\hline Elevated Blood Glucose & \\
\hline Yes & \\
\hline No & \\
\hline
\end{tabular}


Table 2: Factors Associated with Increased Risk of Diabetes Mellitus Among Doctors

\begin{tabular}{|c|c|c|c|c|c|}
\hline & $\begin{array}{l}\text { Low Diabetic } \\
\text { Risk } n(\%)\end{array}$ & $\begin{array}{l}\text { Increased } \\
\text { Diabetic Risk } \\
n(\%)\end{array}$ & $O R$ & $95 \% \mathrm{Cl}$ & P-value \\
\hline Gender & & & & & \\
\hline Male & $83(75.5)$ & $27(24.5)$ & 1.77 & $0.95-3.13$ & 0.050 \\
\hline Female & $52(63.4)$ & $30(36.3)$ & & & \\
\hline Age & & & & & \\
\hline$<45$ years & 101(81.5) & $27(18.5)$ & 4.39 & $2.28-8.47$ & $<0.001$ \\
\hline$\geq 45$ years & $34(50.0)$ & $34(50,0)$ & & & \\
\hline $\begin{array}{l}\text { Body Mass } \\
\text { Index }\end{array}$ & & & & & \\
\hline$>25 \mathrm{~kg} / \mathrm{m}^{2}$ & $103(85.8)$ & $17(14.2)$ & 7.57 & $\begin{array}{l}3.79- \\
15.14\end{array}$ & $<0.001$ \\
\hline$\geq 25 \mathrm{~kg} / \mathrm{m}^{2}$ & $32(44.4)$ & $40(55.6)$ & & & \\
\hline $\begin{array}{l}\text { Abdominal } \\
\text { Obesity }\end{array}$ & & & & & \\
\hline Yes & $127(79.4)$ & $33(20.6)$ & 11.55 & $\begin{array}{l}4.76- \\
28.03\end{array}$ & $<0.001$ \\
\hline No & $8(25.0)$ & $24(75.0)$ & & & \\
\hline $\begin{array}{l}\text { Physical } \\
\text { Inactivity }\end{array}$ & & & & & \\
\hline Yes & $107(80.4)$ & $39(19.6)$ & 1.76 & $0.88-3.54$ & 0.08 \\
\hline No & $28(60.9)$ & $18(39.1)$ & & & \\
\hline $\begin{array}{l}\text { Daily } \\
\text { Consumption } \\
\text { of Vegetable } \\
\text { and Fruit diet }\end{array}$ & & & & & \\
\hline Yes & $41(80.4)$ & $10(19.6)$ & 2.05 & $0.95-4.45$ & 0.046 \\
\hline No & $94(66.7)$ & $47(33.3)$ & & & \\
\hline $\begin{array}{l}\text { Family History } \\
\text { of DM }\end{array}$ & & & & & \\
\hline Yes & $111(75.0)$ & $37(25.0)$ & 2.50 & $1.24-5.04$ & 0.009 \\
\hline No & $24(54.5)$ & $20(45.5)$ & & & \\
\hline Hypertension & & & & & \\
\hline Yes & $27(62.8)$ & $16(37.2)$ & 0.64 & $0.31-1.31$ & 0.150 \\
\hline No & $108(72.5)$ & $41(27.5)$ & & & \\
\hline
\end{tabular}

Fifty $(26 \%)$ were overweight while $22(11.5 \%)$ were obese. Abdominal obesity was present in 32 (16.7\%), physical inactivity was reported in 46(24\%), 51(26.6\%) consume vegetable/fruits daily. Family history of diabetes mellitus was present in 49 (25.5\%), $43(22.4 \%)$ had blood pressure $\geq 140 / 90 \mathrm{mmHg}$ while $6(3.1 \%)$ had elevated random blood glucose. (Table 2) 
Table 3: Predictors of Increased Risk of Diabetes Mellitus Among Doctors

\begin{tabular}{|l|l|l|l|}
\hline & Adjusted Odd Ratio & $95 \% \mathrm{Cl}$ & P-value \\
\hline Age & 9.08 & $3.13-26.33$ & $<0.001$ \\
\hline Gender & 1.82 & $0.81-4.71$ & 0.214 \\
\hline BMI & 11.41 & $4.14-31.45$ & $<0.001$ \\
\hline Physical Inactivity & 1.37 & $0.52-3.64$ & 0.528 \\
\hline Family History of DM & 9.93 & $3.25-30.39$ & $<0.001$ \\
\hline Abdominal Obesity & 6.66 & $2.08-21.29$ & 0.001 \\
\hline $\begin{array}{l}\text { Daily consumption of } \\
\text { vegetable and fruit diet }\end{array}$ & 3.11 & $1.03-9.37$ & 0.044 \\
\hline
\end{tabular}

Table 4: Correlation between Random Blood Glucose, Age, Waist Circumference, Body Mass Index and Total Diabetes Mellitus Risk Score

\begin{tabular}{|l|l|l|}
\hline Parameter & $R$ & P value \\
\hline Age & 0.127 & 0.080 \\
Waist Circumference & 0.249 & $<0.001$ \\
\hline Body Mass Index & & \\
& 0.162 & 0.025 \\
Total Diabetes Mellitus Scores & 0.139 & 0.055 \\
\hline
\end{tabular}

This study showed that $29.7 \%$ of the medical doctors who were assessed had increased 10 year risk of type 2 diabetes mellitus. Among those with increased risk; $14.1 \%$ had moderate to high 10 year risk of developing DM. (Figure 1) Among those that had increased 10 year risk of developing DM, there was a higher proportion of females compared to males $(36.3 \% \mathrm{vs} 24.5 \%, \mathrm{p}=0.050)$. Significant factors associated with increased type $2 \mathrm{DM}$ risks were age $\geq 45$ years ( OR: 4.39; CI: 2.28-8.47; $\mathrm{p}=<0.001$ ); BMI $\geq 25$ $\mathrm{kg} / \mathrm{m}^{2}$ (OR: 7.57; CI: 3.79-15.14; $\mathrm{p}=<0.001$ ); abdominal obesity (OR: 11.55; CI: 4.76-28.03; $\mathrm{p}=<0.001$ ); daily consumption of vegetable and fruit diet (OR:2.05; CI:0.954.45; $\mathrm{p}=0.046$ ); family history of DM (OR:2.50; CI: 1.24 5.04; $\mathrm{p}=0.009)$. Table 2

Significant predictors of increased DM risk on binary regression analysis were age $\geq 45$ years (AOR:9.08; CI 3.1326.33; $\mathrm{p}=<0.001$ ) ; BMI $\geq 25 \mathrm{~kg} / \mathrm{m}^{2}$ (AOR:11.41; CI:4.1431.45; $\mathrm{p}=<0.001)$; family history of DM (AOR:9.93; CI:3.2530.39; $\mathrm{p}=<0.001 ; \mathrm{p}=$ ) ; abdominal obesity (AOR:6.66; CI:2.08-21.29; $\mathrm{p}=<0.001)$ and infrequent dietary intake of fruits and vegetable(AOR:3.11;CI:1.03:9.37: $\mathrm{p}=0.04)$ Table 3

There was a positive correlation between random blood glucose and age $(\mathrm{r}=0.127, \mathrm{p}=0.080)$; random blood glucose and waist circumference $(\mathrm{r}=0.249, \mathrm{p}=<0.001)$; total diabetes mellitus risk score $(\mathrm{r}=0.139, \mathrm{p}=0.055)$; and random blood glucose and body mass index $(\mathrm{r}=0.162, \mathrm{p}=$ 0.025). (Table 4).

\section{Discussion}

Majority of the respondents were young and there was male preponderance in this study which is similar to some previous studies involving medical doctors ${ }^{14,15}$. However, some other studies which involved doctors and other groups of health workers as participants had female preponderance ${ }^{16-18}$.

This study showed that $29.7 \%$ of the medical doctors who were assessed had increased 10-year risk of type 2 diabetes mellitus. Among those with increased risk; 14.1\% had moderate to high risk 10 year risk of developing DM. A higher proportion $(36.3 \%)$ of females had increased 10 year risk of developing type $2 \mathrm{DM}$ compared to males $(24.5 \%)$. This is comparable with findings of Omech et $\mathrm{al}^{13}$ who reported higher diabetic risk in females.

The prevalence of obesity among the doctors in our study was $11.5 \%$ which is comparable with $13.6 \%$ reported among Nigerian doctors in Southern part of Nigeria and $12.5 \%$ reported among some health workers in Ghana ${ }^{14,18}$. Our finding was however; lower than $23.2 \%$ reported among health care providers in a teaching hospital in Plateau State, Nigeria $^{19}$. This difference may be related to the fact that our study involved only doctors while the study done in Plateau State, Nigeria involved both the doctors and other 
health workers. The prevalence of obesity in our study is also comparable with reports from studies conducted among Canadian and Estonian doctors where prevalence rates of $8 \%$ and $9 \%$ were reported respectively ${ }^{20,21}$. Our study showed that the doctors with higher BMI $(\geq 25 \mathrm{~kg} / \mathrm{m} 2)$ have eleven fold risk of developing type $2 \mathrm{DM}$ in 10 years.

Abdominal obesity was present in $16.7 \%$ of our study participants which is comparable with $13.9 \%$ reported among health care workers in a tertiary health centre in Bayelsa, Nigeria ${ }^{16}$.

However, our finding is lower than $37.3 \%$ reported in a previous study among Nigerian doctors ${ }^{14}$. This difference may be partly due to difference in criteria used to diagnose abdominal obesity. Our study used waist circumference of greater than $88 \mathrm{~cm}$ and $102 \mathrm{~cm}$ in males and females respectively unlike the previous study by Ambakederemo et a $1^{14}$ where a stricter criteria of greater than $80 \mathrm{~cm}$ and 94 $\mathrm{cm}$ were used. Higher prevalence rate of abdominal obesity was reported in a study conducted among health workers in Plateau State, Nigeria ${ }^{19}$. This difference may be related to the fact that our study involved only the doctors while the study done in Plateau State, Nigeria involved both the doctors and other health workers. . Our study showed that the doctors with abdominal obesity have about seven fold risk of developing type $2 \mathrm{DM}$ in 10years

The findings in our study is in keeping with reports of Uloko et $\mathrm{al}^{1}$ in a systematic review of studies on DM in Nigeria. They reported obesity as an established risk factor for type 2 DM among Nigerians. Both generalized and central obesity are associated with increased amount of non-esterified fatty acids, glycerol, cytokines, pro-inflammatory markers that are involved in the development of insulin resistance and diabetes mellitus ${ }^{22}$.

Elevated blood pressure of $\geq 140 / 90 \mathrm{mmHg}$ was found in $21 \%$ of our respondents. This is comparable to reports of previous studies conducted among doctors ${ }^{14,23}$. Ambakederemo et $\mathrm{a}^{14}$ and Ordinioha ${ }^{23}$ reported prevalence of $22.1 \%$ and $21.3 \%$ respectively in different studies among doctors in Southern part of Nigeria. This is also similar to findings of Egbi et $\mathrm{a}^{16}$ who reported elevated blood pressure in $22.5 \%$ of hospital workers in a tertiary hospital in Bayelsa State. Our finding was lower than 16.1\% reported among health workers in Ghana during an annual medical screening exercise. ${ }^{18}$ There was a higher proportion of doctors with hypertension in our study who had increased type $2 \mathrm{DM}$ risk, but it was not statistically significant. Adequate physical activity was self reported by $76 \%$ of the respondents which is higher than $65.8 \%$ reported among physicians in Saudi Arabia, ${ }^{24}$ but lower than $92 \%$ reported among Estonian physicians. ${ }^{21}$ However, our finding is at variance with some previous reports from Nigeria. Ambakederemo et $\mathrm{al}^{14}$ and Aghaji et $\mathrm{al}^{15}$ reported that $25.4 \%$ and $38.1 \%$ of their respective study participants who were only doctors had adequate physical activity. Also, Iwuala et $\mathrm{al}^{25}$ reported adequate physical activity in $20.8 \%$ of the health care provider in a study conducted in Lagos, Southwest Nigeria. This contrast may be related to the difference in the methodology used in assessing physical activity. For example, Iwuala et $\mathrm{al}^{25}$ used International Physical Activity Questionnaire-SF (IPA-SF), which is a standardized and more objective instrument. Also, the population in their study comprised of various types of health workers unlike ours that involved only the medical doctors whose routine clinical work commonly is associated with some form of physical activities. Although, there was a higher proportion of doctors who reported physical inactivity in our study with increased type $2 \mathrm{DM}$ risk, it was not statistically significant. Physical inactivity is associated with insulin resistance, obesity and other cardiovascular risk factors. ${ }^{26,27}$ In a multiethnic study by Joseph et $\mathrm{al}^{28}$, higher physical activity was inversely associated with incident type $2 \mathrm{DM}$. Physical activity reduces blood glucose by increasing GLUT-4 mediated glucose uptake into muscle; reduction in insulin resistance, body weight, adiposity and inflammation ${ }^{29,30}$.

Family history of diabetes mellitus was present in $25.5 \%$ of our respondents. This is similar to $27.4 \%$ reported in a study done in Southern Nigeria that involved only the medical doctors, but higher than $17.3 \%$ reported in a study conducted among hospital workers in Bayelsa ${ }^{14,16}$. Our study showed that there was a tenfold increased risk of developing type 2 DM in those with family history of DM. Family history of DM is a strong independent risk factor for developing DM ${ }^{31}$. It has been reported that first degree relatives of type 2 DM patients have up to $40 \%$ higher chance of developing the disease ${ }^{32}$. Therefore, there is need to be more aggressive in addressing other modifiable risk factors for DM in these group of individuals.

About $27 \%$ of the doctors in our study consumed vegetables and fruits daily which is comparable with $25.4 \%$ reported by Ambakederemo et $\mathrm{a}^{14}$ among doctors in Southern Nigeria. However, Frank et $\mathrm{al}^{20}$ reported better consumption of fruits and vegetables amongst Canadian physicians; more than $50 \%$ of females and about $34 \%$ of them consumed fruits daily. Inadequate consumption of fruits and vegetables has been established as a risk factor for developing type $2 \mathrm{DM}^{33}$. Our study showed that doctors who infrequently consumed fruits and vegetables have three fold increased risk of developing type $2 \mathrm{DM}$ over ten years. Systematic review of prospective cohort studies by $\mathrm{Li}$ et al ${ }^{34}$ showed that adequate dietary intake of fruits and vegetables reduces the risk of type 2 DM. Fruits and vegetables contain flavonoids and antioxidants that could reduce the risk of type $2 \mathrm{DM}$ by mitigating oxidative stress that influence uptake of glucose and also increasing insulin sensitivity ${ }^{35-37}$.

Elevated random blood glucose was present in $3.1 \%$ of our study participants. This is comparable with $2.7 \%$ reported among health care workers in Southern Nigeria, but lower than $4.5 \%$ reported among the medical doctors by Ambakederemo et $\mathrm{a}^{14}$.There was positive correlation between random blood glucose, age, waist circumference and BMI. In our study, age $\geq 45$ years is associated with a nine fold increased risk of developing DM.

Previous studies have corroborated the association between blood glucose, body mass index and age ${ }^{38.39}$. Aging and obesity are associated with insulin resistance that may predispose to increase in blood glucose. Therefore weight reduction is also important in reducing the risk of developing type 2 DM especially amongst those who have other additional risk factors such as family history.

The limitation of this study is that blood pressure and blood glucose were only assessed once. It would have been better assessed on two different occasions to confirm the diagnoses of hypertension and diabetes mellitus. Also, glycated haemoglobin was not assessed in the study participants. However, the strength of this study lies in the fact that it is one of the few studies conducted in Nigeria to the best 
of our knowledge that assessed type 2 diabetic risks among medical doctors.

In conclusion, there was increased 10 -year DM risk in about $30 \%$ of the participants which was more common among females. There is an urgent need to promote healthy lifestyle practices among doctors. Physicians should make conscious efforts to practice what they know.

\section{Conflict of Interest}

None

\section{References}

1. Uloko AE, Musa MB, Ramalan MA, Gezawa ID, Puepet FH, Uloko AT et al. Prevalence and Risk Factors for Diabetes Mellitus in Nigeria: A Systematic Review and MetaAnalysis. Diabetes Ther. 2018;9(3): 1307-1316

2. International Diabetes Federation. Diabetes atlas. 8th ed. Brussels: International Diabetes Federation; 2017

3. Chineye S, Uloko AE, Ogbera AO, Ofoegbu EN, Fasanmade OA, Fasanmade AA et al. Profile of Nigerians with diabetes mellitus Diabcare Nigeria study group (2008): Results of a multicenter study. Indian J Endocrinol Metab. 2012;16(4):558-564

4. Ogbera AO, Chinenye S, Onyekwere A, Fasanmade O. Prognostic indices of diabetes mortality. Ethn Dis. 2007 Autumn;17(4):721-5.

5. Ogbera AO, Awobusuyi J, Unachukwu C, Fasanmade O. Clinical features, predictive factors and outcome of hyperglycaemic emergencies in a developing country, BMC Endocr Disord. 2009; 9: 9.doi: $10.1186 / 1472-6823-9-9$

6. van Dieren S, Beulens JW, van der Schouw YT, Grobbee DE, Neal B. The global burden of diabetes and its complications: an emerging pandemic. Eur J Cardiovasc Prev Rehabil. 2010;17(1):3-8

7. Bommer C, Sagalova V, Heesemann E, Manne-Goehler J, Atun R, Bärnighausen T et al. Global Economic Burden of Diabetes in Adults: Projections From 2015 to 2030. Diabetes Care 2018 ; dc171962. doi. org/10.2337/dc17-1962

8. Ababio GK, Bosomprah S, Olumide A, Aperkor N, Aimakhu C, Oteng-Yeboah A et al. Predictors of quality of life in patients with diabetes mellitus in two tertiary health institutions in Ghana and Nigeria. Niger Postgrad Med J 2017;24:48-55.

9. Gebremedhin T, Workicho A, Angaw DA. Health related quality of life and its associated factors 2019;7:e000577. doi:10.1136/ bmjdrc-2018-00057

10. Onyekwelu J. Health-seeking behavior of medical directors in Nigeria. Niger J Gen Pract 2019;17:12-5

11. Franch-Nadal J, Mediavilla-Bravo J, Mata-Cases M, Mauricio D, Asensio D, Sarroca J. Prevalence and control of type 2 diabetes mellitus among primary care physicians in Spain. PRISMA Study. Endocrinol Diabetes Nutr. 2017;64(5):265-271

12. International Diabetes Federation, Clinical Guidelines Task Force Global Guideline for Type 2 Diabetes, 2012. Accessible from: http:// www.idf.org/sites/default/files/IDFGuideline-for-Type-2-Diabetes.pdf

13. Omech B, Mwita JC, Tshikuka J, Tsima B, Nkomazna O, Olak KA. Validity of the Fi nish Diabetes Risk Score for Detecting Undiagnosed Type 2 Diabetes among General Medical Outpatients in Botswana. Journal of Diabetes Research Volume 2016, Article ID 4968350, 7 pages. Accessible from: http://dx.doi.org/10.1155/2016/4968350

14. Ambakederemo TE, Chikezie EU. Assessment of some traditional cardiovascular risk factors in medical doctors in Southern Nigeria. Vasc Health Risk Manag. 2018; 14: 299-309.

15.Aghaji MN. Doctors lifestyle in Enugu, Nigeria. East Afr Med J 2000;77:480-4

16. Egbi OG, Rotifa S, Jumbo J. Prevalence of hypertension and its correlates among employees of a tertiary hospital in Yenagoa, Nigeria. Ann Afr Med 2015;14:8-17

17.Owolabi AO, Owolabi MO, OlaOlorun AD, Amole IO. Hypertension prevalence and awareness among a health workforce in Nigeria. Internet J Med Update 2015;10(2):10-19

18. Osei-Yeboah J, Kye-Amoah KK, Owiredu WK, Lokpo SY, Esson J, Johnson BB et al. Cardiometabolic Risk Factors among Healthcare Workers: A Cross-Sectional Study at the Sefwi-Wiawso Municipal Hospital, Ghana. BioMed Res Int 2018. https://doi. org/10.1155/2018/8904548

19. Dankyau M, Shu'aibu JA, Oyebanji AE, Mamven OV. Prevalence and correlates of obesity and overweight in healthcare workers at a tertiary hospital. J Med Trop 2016;18:55-9

20. Frank E, Segura C. Health practices of Canadian physicians. Can Fam Physician. 2009:55(8);810-811 21.

21. Suija K, Pechter U, Maaroos J, Kalda R, Ratsep A, Oona M, et al. Physical activity of Estonian family doctors and their counselling for a healthy lifestyle: a cross-sectional study. BMC Fam Pract. 2010;11:48 doi.org/10.1186/1471-2296-11-48

22. Al-Goblan AS, Alfi MA, Khan MZ. Mechanism linking diabetes mellitus and obesity. Diabetes Metab Syndr Obes. 2014;7:587-591

23. Ordinioha B. The prevalence of hypertension and its modifiable risk factors among lecturers of a medical school in Port Harcourt, south-south Nigeria: implications for control effort. Niger J Clin Pract. 2013;16(1):1-4.

24. Banday AH, Want FA, Alris FF, Alrayes MF. Alenzi MJ. A crosssectional study on the prevalence of physical activity among primary health care physicians in Aljouf Region of Saudi Arabia. Mater Sociomed. 2015;27(4): 263-266

25. Iwuala SO, Sekoni AO, Olamoyegun MA, Akanbi MA, Sabir AA, Ayankogbe OO. Self reported physical activity among health care professionals in South-West Nigeria. Niger J Clin Pract 2015;18:790795

26. Arteaga A, Bustos P, Soto R, Velasco N, Amigo H. Physical activity and cardiovascular risk factors among Chilean young men and women. Rev Med Chil. 2010; 138:1209-16.

27. Larsson CA, Krøll L, Bennet L, Gullberg B, Råstam L, Lindblad U. Leisure time and occupational physical activity in relation to obesity and insulin resistance: a populationbased study from the Skaraborg Project in Sweden. Metabolism 2012; 61: 590-98. 10.1016/j. metabol.2011.09.010

28. Joseph JJ, Echouffo-Tcheugui JB, Golden SH, Chen H, Jenny NS, Carnethon MR et al. Physical activity, sedentary behaviors and the incidence of type 2 diabetes mellitus: the Multi-Ethnic Study of Atherosclerosis (MESA). Accessible from http://dx.doi.org/ 10.1136/ bmjdrc-2015-000185

29. Colberg SR, Sigal RJ, Fernhall B, Regensteiner JG, Blissmer BJ, Rubin RR et al. Exercise and type 2 diabetes: the American College of Sports Medicine and the American Diabetes Association: joint position statement. Diabetes Care 2010;33:147-167

30. Petersen AM. The anti-inflammatory effect of exercise. J Appl Physiol 2005;98:1154-62

31.Scott RA, Langenberg C, Sharp SJ, Franks PW, Rolandsson O, Drogan D et al. The link between Family History and risk of Type 2 Diabetes is Not Explained by Anthropometric, Lifestyle or Genetic Risk Factors: the EPIC-InterAct Study. Diabetologia. 2013;56(1):60-69.

32. Owen K , Ayres S, Corbett S , Hattersley A. Increased risk of diabetes in first-degree relativesb of young -onset type 2 diabetes patients compared with relatives of those diagnosed later .Diabetes Care 2020;25(3):636-637.

33. Wang P, Fang J, Gao Z,Zhang C, Xie S. Higher intake of fruits ,vegetables or their fiber rduces the risk of type 2 diabetes : A meta- 
analysis .J Diabetes investing .2016;7(1): 56-69.

34. Li M, Fan Y, Zhang X,Hou W, Tang Z.Fruit ande vegetable intake and risk of type 2 diebetes mellitus: meta-analysis of prospective cohort study BMJ Open 2014:5;4(11):e005497. Doi:10.1136/ bmjopen-2014-005497

35. Gordon M. Dietary antioxidants in diseases prevention. Nat Prod Rep 1996; 13:265-273

36. Ceriello A.Motz E. Is oxidative stress the pathogenic mechanism underiying insulin resistance, diabetes, and cardiovascular disease? The common soil hypothesis revisited Arterioscler Thromb vasc Biol 2004; 24:816-823
37. salas-salvado J,Martinz-Gonzalez MA, Bullo M, Ros E The of role diet in the prevention of type 2 diabetes nutr Metab Cardiovasc Dis 2011;21(2):32-48

38. Ko G, Wai H, Tang j.Effect of Age on plasma Glucose levels in Non-diabetic Hong Kong Chinese. Croat Med J. 2006 ;47(5):709-71

39. Veghari G, Sedaghat M, Joshaghani H, Banihashem s, Moharloei P ,Angizeh A et al. The association of fasting blood glucose (FGB) and waist circumference in northern adult in Iran:a population based study, $\mathrm{j}$ Diabetes Metab Discord . 2014;13:2.doi:10.1186/2251-6581-13-2. 